NASA Technical Memorandum 106711

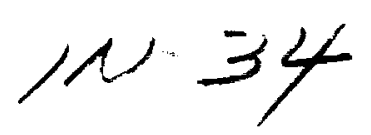

56594

217

\title{
Experimental and Computational Investigation of the Tip Clearance Flow in a Transonic Axial Compressor Rotor
}

Kenneth L. Suder

National Aeronautics and Space Administration

Lewis Research Center

Cleveland, Ohio

and

Mark L. Celestina

Sverdrup Technology, Inc.

Lewis Research Center Group

Brook Park, Ohio

Prepared for the

39th International Gas Turbine and Aeroengine Congress and Exposition sponsored by the American Society of Mechanical Engineers

The Hague, Netherlands, June 13-16, 1994

NASA

National Aeronautics and Space Administration
(NASA-TM-106711) EXPERIMENTAL ANO COMPUTATIONAL INVESTIGATION OF THE

TIP CLEARANCE FLOW IN A TRANSONIC

AXIAL COMPRESSOR ROTOR (NASA.

Lewis Research Center)

$17 \mathrm{p}$
N95-31738

Unclas

G3/34 0056594 


\title{
EXPERIMENTAL AND COMPUTATIONAL INVESTIGATION OF THE TIP CLEARANCE FLOW IN A TRANSONIC AXIAL COMPRESSOR ROTOR
}

\author{
Kenneth L. Suder \\ NASA-Lewis Research Center \\ Cleveland, Ohio \\ Mark L. Celestina \\ Sverdrup Technology Inc. \\ Lewis Research Center Group \\ Cleveland, Ohio
}

\begin{abstract}
Experimental and computational techniques are used to investigate tip clearance flows in a transonic axial compressor rotor at design and part speed conditions. Laser anemometer data acquired in the endwall region are presented for operating conditions near peak efficiency and near stall at $100 \%$ design speed and at near peak efficiency at $60 \%$ design speed. The role of the passage shock / leakage vortex interaction in generating endwall blockage is discussed. As a result of the shock / vortex interaction at design speed, the radial influence of the tip clearance flow extends to 20 times the physical tip clearance height. At part speed, in the absence of the shock, the radial extent is only 5 times the tip clearance height. Both measurements and analysis indicate that under part-speed operating conditions a second vortex, which does not originate from the tip leakage flow, forms in the endwall region within the blade passage and exits the passage near midpitch. Mixing of the leakage vortex with the primary flow downstream of the rotor at both design and part speed conditions is also discussed.
\end{abstract}

\section{NOMENCLATURE}

$\begin{array}{ll}\text { Mrel } & \text { Relative Mach number } \\ \mathbf{P}_{\text {ref }} & \text { Standard day total pressure, } 101325 \mathrm{n} / \mathrm{m}^{2} \\ \text { ps } & \text { Denotes pressure surface } \\ \mathrm{q}_{\text {rel }} & \text { Relative dynamic head normalized by } \mathrm{P}_{\text {ref }} \\ \mathbf{R} & \text { Radial Direction } \\ \text { ss } & \text { Denotes suction surface } \\ \mathrm{Z} & \text { Axial Direction } \\ \theta & \text { Circumferential dierection }\end{array}$

\section{INTRODUCTION}

Endwall flow fields continue to be the focus of many research efforts because of their impact on compressor stability and performance. For example, Wisler (1985) reports that an increase in tip clearance from $1.4 \%$ to $2.8 \%$ of blade height in a low speed multistage compressor resulted in a 1.5 point efficiency penalty, an $11 \%$ reduction in flow range, and a $10 \%$ reduction in peak pressure rise. The accumulation of low momentum fluid near the blade tip and the vortical structure of the flow downstream of low speed compressors has been documented by Inoue et al. (1986), Inoue and Kuroumari, (1989), McDougall (1990), Stauter (1992), and others. Inoue and Kuroumari (1989) have also provided data conceming the endwall flow field within the compressor blade passage in a low speed compressor. Although these investigations have shed light on the endwall flow in low speed machines, there is much less information concerning the endwall flow fields within the blade passage in high speed compressors. Measurements reported have been primarily limited to high-response static pressure data over the rotor tip, for example those of Copenhaver et al. (1992).

Our understanding of the endwall flow has been enhanced by models of the tip clearance flow developed from detailed measurements in the endwall region of low speed compressors. For example, Storer and Cumpsty (1993) have shown that the losses due to the tip leakage flow are primarily associated with the mixing process that takes place between the leakage flow and the throughflow, and that these losses can be predicted from the angle formed between the clearance flow and the throughflow. In addition, Chen et al. (1991) developed a model to describe the trajectory of the leakage vortex. These modelling efforts have yielded reasonable agreement with data available from low speed compressors.

Due to the limited availability of detailed measurements, our understanding of the endwall flow in high speed compressors has been largely obtained from numerical simulations. In high 
speed compressors the endwall flow is further complicated by the interaction between the rotor passage shock and the tip leakage flow. Adamczyk et al. (1993) and Copenhaver et al. (1992) have used 3D Navier-Stokes solvers to sudy this shock / vortex interaction. Adamczyk studied the effect of variations in tip clearance on the performance of a transonic rotor, and showed that the shock / vortex interaction plays a major role in determining the compressor flow range. Although such efforts have improved our understanding of the endwall flow over the last 5-10 years, we continue to have difficulty in accurately predicting the blockage in the endwall region, especially in multistage compressors. It is clear that there is a need for detailed experimental data within high speed compressors to assess numerical simulations and models, and to enhance our understanding of the shock / vortex interaction and its affect on blockage.

The objectives of this investigation are 1) to study the shock / vortex interaction in a high speed compressor and its impact on the endwall blockage, and 2) to study the development of the tip leakage vortex within and downstream of the compressor rotor with and without the presence of a rotor passage shock. In order to achieve these objectives, the present effort couples experimental measurements with 3D Navier-Stokes numerical simulations of the endwall flow within a highly loaded transonic axial compressor rotor. Measurements and numerical simulations are presented for both transonic and subsonic operating conditions. The numerical simulations are presented to illustrate the interaction between the tip leakage flow and the rotor passage shock and the generation of blockage which results from this interaction. Laser anemometer measurements acquired at design speed for operating conditions near peak efficiency and near stall are presented to show the effect of varying the rotor backpressure on the shock / vortex interaction and endwall blockage. Additional measurements acquired within and downstream of the blade row are presented to illustrate the mixing of the leakage vortex with the primary flow.

\section{TEST FACILITY}

The experiment was performed in the single stage transonic compressor facility at the NASA Lewis Research Center. This is an open loop facility with atmospheric inlet and exit conditions. The mass flow rate is measured by an orifice plate located far upstream of the compressor and a downstream throttle valve is used to backpressure the rotor. A detailed description of the facility is given by Urasek and Janetzke (1972).

The test compressor was designed as an inlet stage for a core compressor and is designated as NASA Stage 37. For this experiment the rotor was tested in isolation to avoid the interaction effects generated by the presence of an upstream inlet guide vane or downstream stator blade row. The rotor design pressure ratio is 2.106 at a mass flow of $20.19 \mathrm{~kg} / \mathrm{s}$. The inlet relative Mach number is 1.13 at the hub and 1.48 at the tip at the design speed of $454 \mathrm{~m} / \mathrm{s}$. The rotor aspect ratio is 1.19 and the hub/tip radius ratio is $\mathbf{0 . 7 0}$. Details of the rotor aerodynamic design were reported by Reid and Moore (1978). Overall aerodynamic performance of the stage was reported by Moore and Reid (1980).
The rotor tip clearance was measured using both a Rotodata touch probe and rub probes. The uncertainty in the touch probe and rub probe clearance measurements is estimated to be 0.05 $\mathrm{mm}(0.002 \mathrm{in}$.). Touch probe measurements were obtained at 10 , 50 , and $90 \%$ of rotor chord at one circumferential location on the compressor casing and indicated a design speed tip clearance of $0.330 \mathrm{~mm}$ with a variance of $0.005 \mathrm{~mm}$. The rub probes were located in three different regions around the circumference and indicated an average tip clearance of $0.320 \mathrm{~mm}$ with a variance of $0.120 \mathrm{~mm}$. Both the touch probe and the rub probes measure the longest blade and therefore yield a conservative measure of the tip clearance. An inspection of the rotor wheel assembly at the conclusion of testing revealed that the variance in tip radius was $\pm 0.075 \mathrm{~mm}$. Therefore, $0.075 \mathrm{~mm}$ was added to the average clearance probe measurement of $0.325 \mathrm{~mm}$ to arrive at an estimated clearance of $0.400 \mathrm{~mm}(0.016 \mathrm{in}$.) which corresponds to $0.5 \%$ of blade span and $0.7 \%$ of rotor tip chord.

\section{LASER ANEMOMETER SYSTEM}

Detailed flow field measurements are acquired with a two color fringe-type laser anemometer system. The two anemometer channeis are configured to simultaneously acquire the tangential and axial velocity components. One of the laser beams in each of the two channels is frequency shifted to enable detection of flow reversals. The effective length of the measurement volume is reduced by using a short focal length $f 2$ focussing lens and by using optical masks in the collection optics. The measurement volume is $60 \mu \mathrm{m}$ in diameter and has an effective length of $0.5 \mathrm{~mm}$, which corresponds to less than $1 \%$ of the blade span. The uncertainties in the laser anemometer velocity and flow angle measurements are estimated as $1 \%$ and 0.5 degrees, respectively.

Polystyrene latex spheres are injected into the facility ducting far upstream of the compressor rotor and serve as the seed material for the laser anemometer system. The seed particles are manufactured at NASA-Lewis using the procedure developed by Nichols (1987). Scanning electron microscope inspections of the seed particles within a given batch indicate that they are spherical in shape and uniform in size. However, the mean particle diameter varies from batch-to-batch over a range of 0.7-0.9 $\mu \mathrm{m}$. Laser anemometer measurements acquired under identical operating conditions with particles manufactured in different batches indicate that there are no differences in the measurements attributable to particle size variations within this range.

A $2.54 \mathrm{~mm}$ thick alumina silica window, which is contoured in both the axial and circumferential directions to conform to the rotor flowpath, provides optical access to the flow field. The window extends more than one rotor chord upstream and three rotor chords downstream, providing continuous access throughout the rotor flow field.

Laser anemometer measurements are acquired upstream, within, and downstream of the rotor along the $90 \%$ and $95 \%$ span streamsurfaces shown in Figure 1 at axial intervals of approximately $5 \%$ rotor chord. The measurements are synchronized to the rotor circumferential position using a high frequency clock and supporting electronics as described in Hathaway et al. (1993). At each axial 


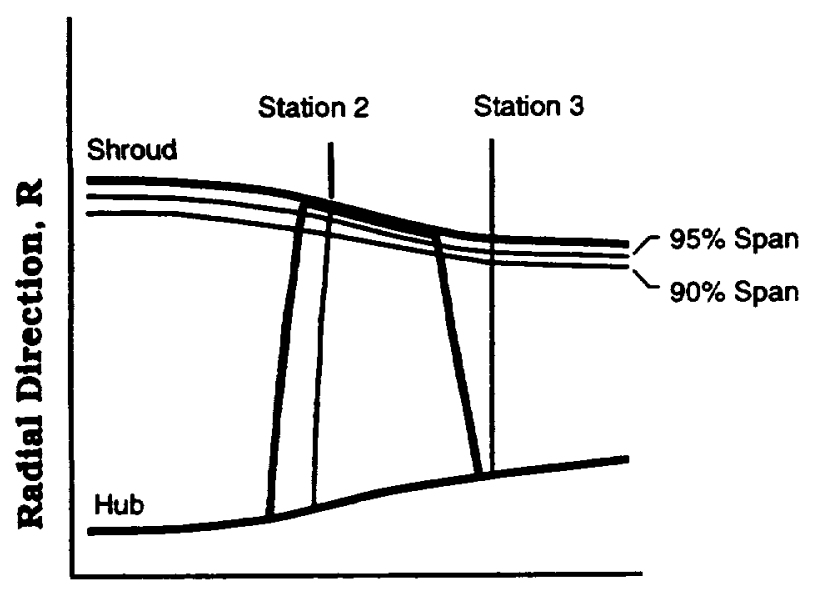

Arial Direction, 2

FIGURE 1. LASER ANEMOMETER SURVEY PLANES.

location, data are acquired across all blade passages at a circumferential resolution of 184 points across a blade pitch. The flow field is also surveyed along cross-channel planes such as stations 2 and 3 shown in Figure 1, nominally over the outer 20\% of span in radial increments of $2 \%$ span. Measurements were made as close as $1 \mathrm{~mm}$ (0.040 in.) from the shroud, which corresponds to 2.5 times the clearance gap.

All laser anemometer results presented are based on the velocity distribution across an averaged blade passage, which is calculated by ensemble-averaging the measurements acquired in each individual blade passage. The relative Mach number is calculated from the relative velocity and the local speed of sound at each point in the flow field using the procedure discussed by Strazisar (1989). The radial velocity component, which is not measured by the laser anemometer, is ignored in the calculation of the measured relative Mach number. Using the predicted flow fields generated by the 3D Navier-Stokes simulations described below, we calculated the Mach number distributions throughout the flow field with and without the radial velocity component included and found that ignoring the radial velocity component resulted in a maximum error of only $2 \%$. All measured Mach number distributions presented below do not include the radial velocity component, while all predicted Mach number distributions do include the radial velocity component.

\section{COMPUTATIONAL PROCEDURE}

The analysis code used in the present study solves the ReynoldsAveraged form of the Navier-Stokes equations. Details of the code can be found in Adamczyk et al. (1989). The flow in the clearance gap was simulated using a model suggested by Kirtley et al. (1990), which treats the clearance flow as an orifice flow with no loss in mass, momentum, or energy. The effect of the vena contracta which occurs in orifice flows is accounted for by using a discharge coefficient, which makes the effective tip clearance gap smaller than the actual clearance. A discharge coefficient of 0.5 is used for all results presented herein.
The grid used in the simulations had 51 cells in the radial direction, 41 cells in the circumferential direction, and 132 cells were placed between the inlet and exit boundaries, of which 41 were along the blade chord line. The clearance gap was spanned by two cells in the radial direction. The grid in the clearance gap region above the rotor tip is constructed by simply extending the grid below the tip to the shroud while maintaining the tangential distance across the blade passage fixed to its value at the rotor tip. The number of grid points spanning the gap in the radial direction would be too few if one were interested in resolving the details of the flow entering and exiting the gap, as done by Crook (1989). In the present study however, we are interested mainly in the clearance flow interaction with the primary throughflow in the blade passage. Several studies have shown that reasonable estimates of this interaction can be obtained without a detailed description of the flow exiting the gap if one has a good estimate of the gap mass flow. This can be accomplished in a numerical simulation with as few as one grid cell spanning the radial direction if one accounts for the blockage introduced by the vena contracta.

\section{RESULTS \& DISCUSSION}

\section{Design Speed Computational Results}

Computational results generated for operating conditions near peak efficiency and near stall are presented first in order to identify key features associated with the tip clearance flow and to aid in the interpretation of experimental results. Flow field predictions were generated for a clearance of $0.356 \mathrm{~mm}(0.014 \mathrm{in}$.) as well as a larger clearance of $0.584 \mathrm{~mm}(0.023 \mathrm{in}$.) or $0.6 \%$ and $1.0 \%$ of rotor tip chord, respectively. The results indicated that there were no significant qualitative differences in the vortex trajectory or relative Mach number distribution between the predicted endwall flow fields for these two levels of clearance. All numerical results presented below are therefore based on a tip clearance of 0.356 $\mathrm{mm}$ (0.014 in.). Computational results are presented in terms of 1) relative Mach number and relative dynamic head on a bladeto-blade streamsurface at a radius below the blade tip, and 2) pathlines of particles released in the clearance gap. Relative Mach number contours are used to provide a direct comparison with the experimental data, while contours of the relative dynamic head depict the blockage in the blade passage. Pathlines of particles released in the clearance gap are shown to illustrate the formation and trajectory of the leakage vortex. The numerical results indicate that the key flow features associated with the clearance flow occupy the outer $3 \%$ of blade span, and the results are therefore presented on a blade-to-blade streamsurface at $98 \%$ of blade span, which passes through the approximate center of this region.

Predicted relative Mach number contours are shown in Figure 2a. The Mach number contours are drawn in increments of 0.1 and the same color bar is used for both peak efficiency and near stall. At near peak efficiency the passage shock is oblique and is attached to the leading edge, while at near-stall the shock is nearly 


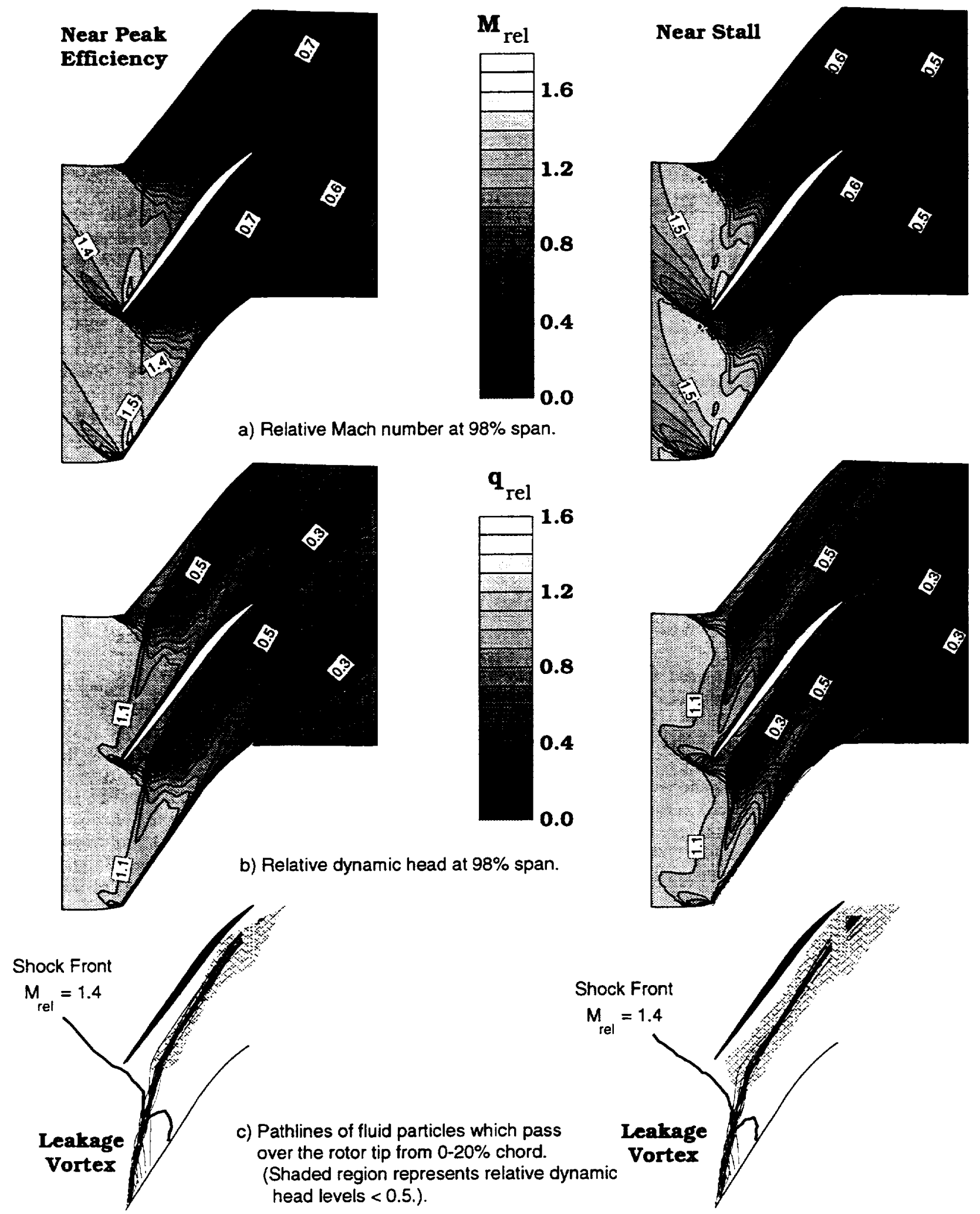

FIGURE 2. COMPUTATIONAL RESULTS AT DESIGN SPEED FOR NEAR PEAK EFFICIENCY (LEFT COLUMN) AND NEAR STALL (RIGHT COLUMN) OPERATING CONDITIONS. 
normal and is detached from the leading edge. The near-stall results indicate a distortion of the passage shock near midpitch and there is evidence of a similar but weaker distortion in the shock front at the near peak efficiency condition. At both operating conditions a region of low Mach number fluid originates near midpitch just downstream of the shock and migrates toward the pressure surface of the blade. At the near peak efficiency condition the fluid in this region merges with the wake downstream of the blade.

Distributions of the relative dynamic head at $98 \%$ span, normalized by inlet total pressure, are presented in Figure $2 b$ to illustrate the correlation between the flow features described above and flow blockage within the blade passage. At the near-stall condition, a region of low dynamic head originates at the leading edge of the blade, crosses through the shock near mid-pitch, and continues downstream near the pressure surface. The dynamic head just downstream of the shock is extremely low, and corresponds to only $20 \%$ of the upstream dynamic head. This represents a severe flow blockage within the center of the blade passage. Similar features are evident at the near peak efficiency condition, although the loss in dynamic head is less severe than at near-stall. A comparison of the relative Mach number to the relative dynamic head contours in Figure 2 indicates that a region of low Mach number coincides with a region of low dynamic head. Therefore, regions of low Mach number are also indicative of blockage.

The origin of the fluid located in the regions of low dynamic head was determined by tracking the pathlines of fluid particles which pass through the rotor tip clearance gap. These pathlines are illustrated in Figure 2c. Note that the pathlines are not constrained radially (in other words the radius changes along a pathline), and that Figure $2 c$ is simply a view of the pathlines as seen by an observer looking radially inward toward the hub. Also shown in Figure $2 c$ is the location of the shock front which is depicted by the relative Mach number contour level of 1.4 and a shaded region representing the relative dynamic head contour level of $\leq 0.5$ from the computational results at $98 \%$ span. The pathlines are shown only for those particles which pass through the clearance gap in the first $20 \%$ of blade chord, since inspection of the pathlines of particles which pass through the clearance gap downstream of $20 \%$ chord indicates that these particles do not contribute substantially to the formation of the clearance vortex. The results in Figure $2 \mathrm{c}$ illustrate that fiuid which passes through the clearance gap in the first $20 \%$ of chord rolls into a vortex and that the path of this vortex coincides with the shock front distortion and the region of low dynamic head downstream of the shock. A comparison of the pathlines and Mach number distributions further shows that the vortex path between the leading edge and the shock front can be inferred from the distortion of the Mach contour lines in this region. Using the relative dynamic head contour of 0.5 to identify the blockage region, we see that the blockage region is larger and is located further upstream for the near stall compared to the near peak efficiency operating condition. Also, note that the leakage vortex penetrates closer to the blade pressure surface at near peak efficiency than at near stall condition. Upstream of the shock the vortex trajectory is nearly identical for the two operating conditions. As the vortex crosses the shock it is diffused by the pressure gradient and is more readily turned by the throughflow.
Since the pressure gradient across the shock is greater at the near stall than at the near peak efficiency operating condition, the vortex experiences a greater diffusion and is turned more by the throughflow at the near stall as compared to the near peak efficiency operating condition.

In summary, the computational results indicate that the clearance flow over the front portion of the rotor chord forms a welldefined vortex which moves toward the pressure side of the blade passage. A distortion of the passage shock arises from the interaction between this vortex and the shock. The severe pressure rise across the shock causes a substantial diffusion of the vortex, resulting in a region of very low dynamic head which occupies almost half of the blade pitch downstream of the shock. (A more quantitative examination of the vortex diffusion will be presented below in the experimental results discussion.) In addition, these features of the vortex are depicted in the relative Mach number distribution, which is important in light of the fact that the relative Mach number is a quantity which can be determined from laser anemometer surveys of the rotor flow field.

\section{Design Speed Experimental Results}

Due to reflections from the window surface and blade tips, 95\% span is the closest approach to the shroud at which laser anemometer measurements were successfully acquired within the rotor. In the previous section the computational results were presented at $98 \%$ span. However the tip clearance flow features, such as the distortion of the passage shock and the development of regions of low relative dynamic head, identified from the computational results presented at $98 \%$ span were representative of those throughout the region of influence of the tip clearance flow (over the outer $3 \%$ of span). Comparisons of the computations to the experiment, though not shown herein, have revealed that the computations predict the correct structure of the leakage vortex but underpredict the radial extent of influence of the tip leakage flow. However, we are only concerned with using the computations to identify the structure of the leakage vortex in this paper. Therefore, the conclusions drawn from the computations at $98 \%$ span are used to interpret the data at $95 \%$ span.

Clearance Vortex Path. Relative Mach number distributions measured on the 95\% span streamsurface at the near peak efficiency and near stall operating points are shown in Figure 3, plotted to the same color scale as that used for the numerical results in Figure $2 \mathrm{a}$. The location of cross-channel planes at $20 \%$, $108 \%$, and $138 \%$ chord, which will be discussed below, is also shown. The white areas in each plot indicate regions in which laser anemometer measurements could not be made due to reflections from the blades and optical blockage of the laser beam paths by the blades. The clearance vortex path upstream of the shock can be inferred from the defiections of the Mach contour lines, and is shown by a broken line. The vortex path is in good agreement with the path predicted by the numerical analysis. The experimental results also confirm the predicted distortion of the shock front. The presence of the blockage region in the pressure surface half of the blade passage downstream of the shock 


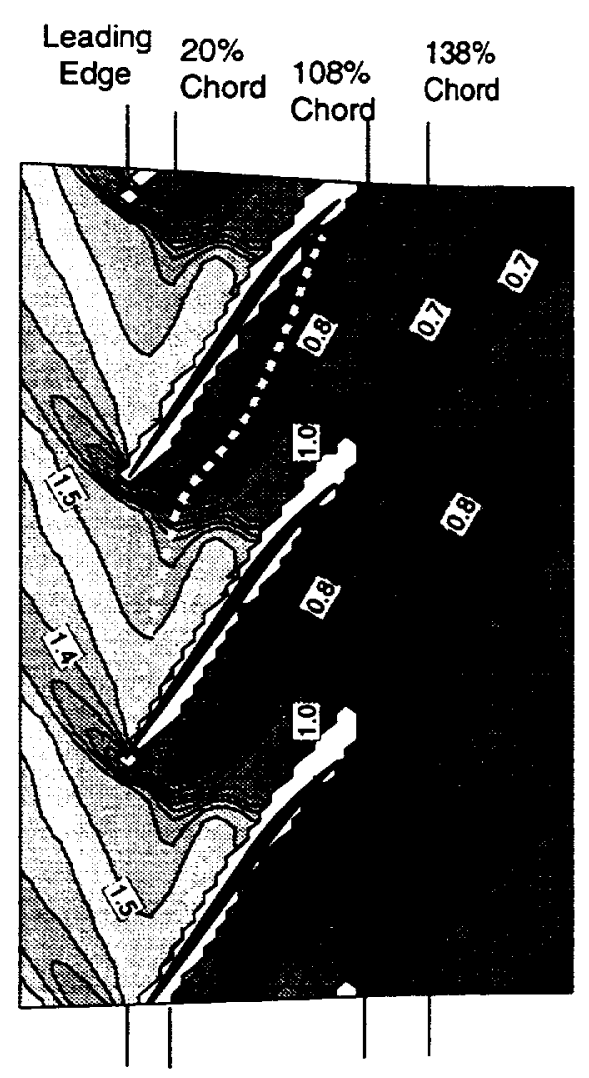

a) Near Peak Efficiency

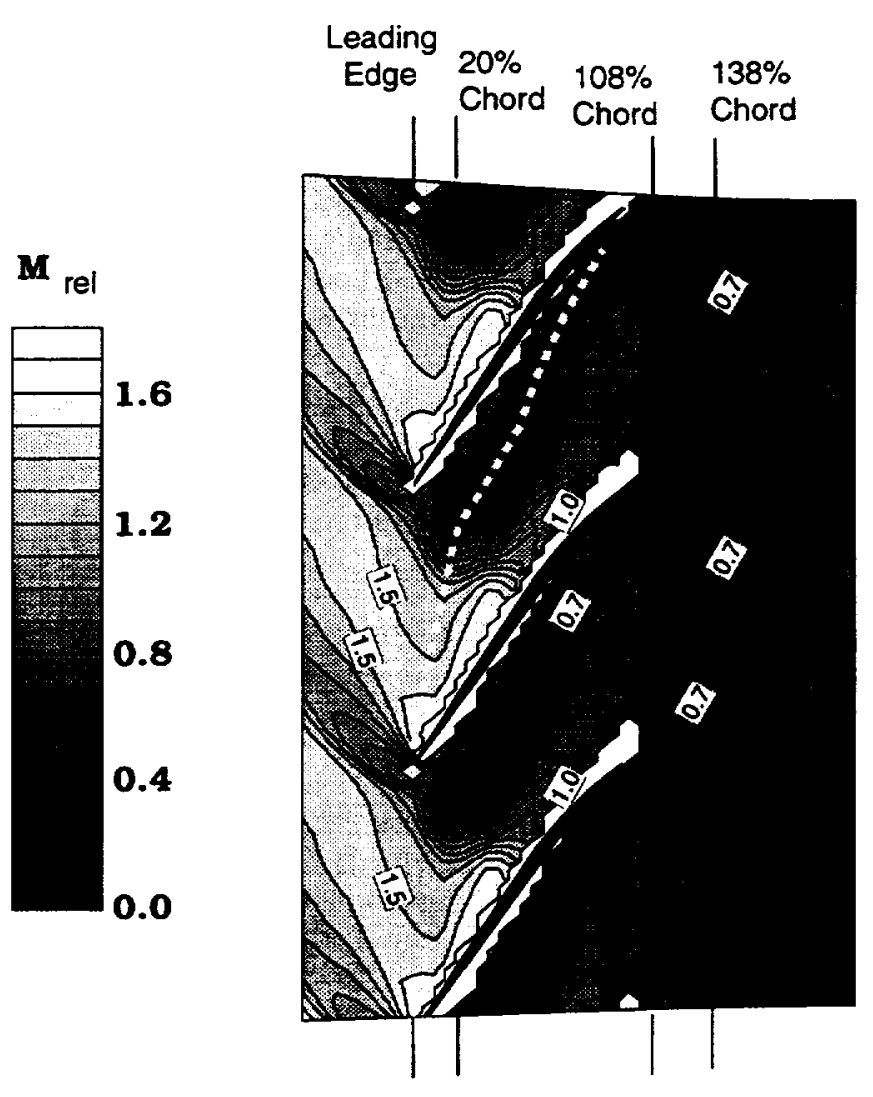

b) Near Stall

FIGURE 3. MEASURED RELATIVE MACH NUMBER CONTOURS AT 95\% SPAN FOR NEAR PEAK EFFICIENCY AND NEAR STALL OPERATING CONDITIONS AT DESIGN SPEED. [........... ESTIMATED CLEARANCE VORTEX PATH].

is also confirmed by the low relative Mach numbers measured in this region. The data indicates that the fluid within the clearance vortex downstream of the shock migrates toward the pressure surface more rapidly than predicted by the numerical analysis, and impacts on the blade pressure surface before reaching the blade trailing edge. The vortex fluid then appears to merge with the rotor wake fluid for both the peak efficiency and the near stall operating conditions. Using the location of lowest Mach number to indicate the 'hear' of the blockage region and the level to represent the severity, the data confirms the computational results in that the blockage becomes more severe and is located further upstream as the rotor backpressure is increased from near peak efficiency to near stall operating conditions.

Clearance Vortex Blockage. Comparison of the bladeto-blade Mach number distributions discussed above to similar results obtained at $90 \%$ span which are not shown here indicates that the upstream relative Mach number and blade incidence angle is virtually identical at $90 \%$ and $95 \%$ span. (The inlet relative Mach number differs by only 0.01 and the blade incidence angle differs by only $0.5^{\circ}$ between $90 \%$ and $95 \%$ span results.) We can therefore assume that differences in the $90 \%$ and $95 \%$ span flow fields within the blade row are due to the influence of the tip clearance flow. We can use this assumption to illustrate the strength of the blockage resulting from the clearance flow by comparing measurements obtained at these two immersions. Figure 4 is a comparison of the relative Mach number distributions measured along the vortex trajectories shown in Figure 3 by the dashed lines. The symbols represent the data acquired at $95 \%$ span and the solid line represents the data acquired at $90 \%$ span. The lightly shaded region represents the influence of the leakage vortex on the Mach number distribution upstream of the shock / vortex interaction and the darker shaded region represents the influence of the leakage vortex downstream of the shock /vortex interaction. The Mach number distributions are identical upstream of the leading edge and nearly identical within the blade passage upstream of the shock / vortex interaction which occurs at approximately $20 \%$ chord, indicating that the vortex has very little influence at $95 \%$ span upstream of the shock. However, the most striking feature shown in Figure 4 is the Mach number difference in the region between the shock and the trailing edge, which is evidence of the blockage generated when the clearance vortex crosses the shock. 


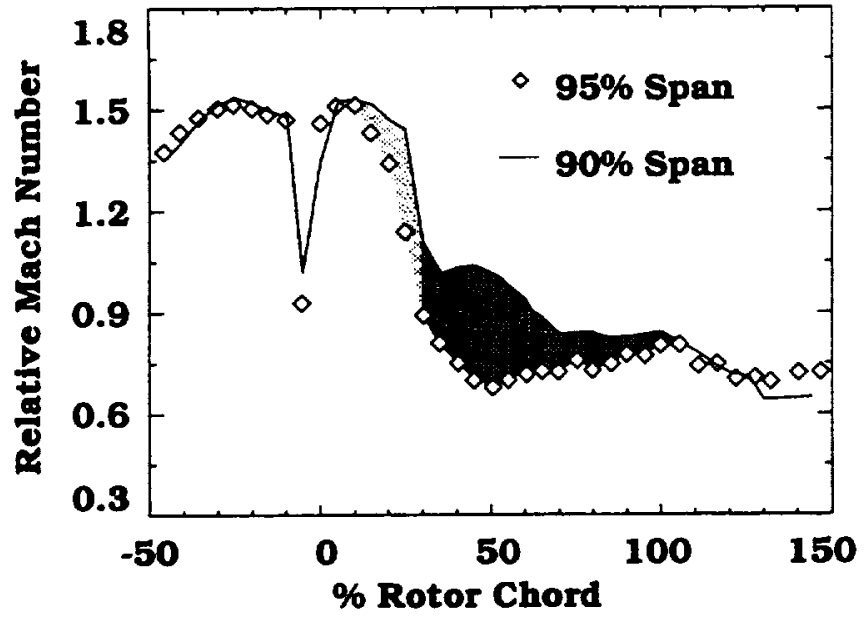

a) Near Peak Efficiency

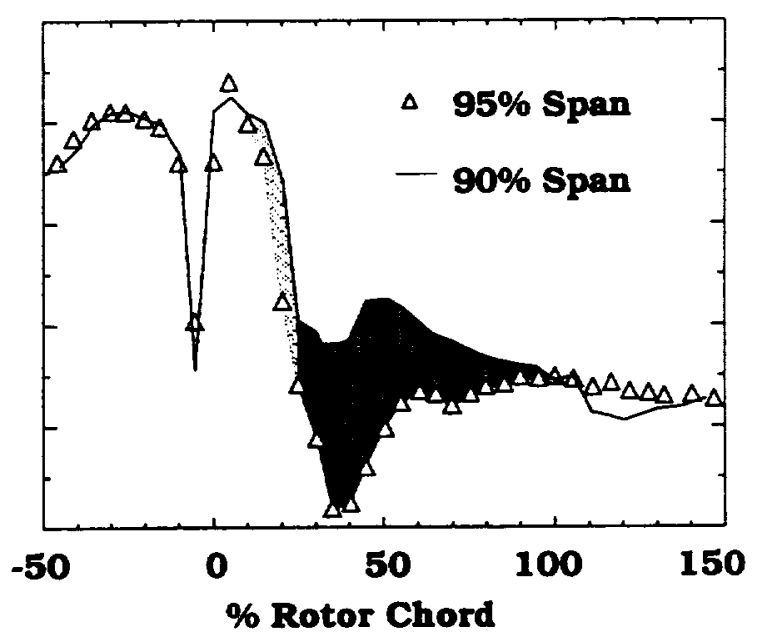

b) Near Stall

FIGURE 4. MEASURED RELATIVE MACH NUMBER DISTRIBUTIONS ALONG THE VORTEX TRANECTORY INDICATING THE BLOCKAGE GENERATED BY THE SHOCK / VORTEX INTERACTION.

Clearance Vortex Impact on Tip Stall. McDougall et al. (1990) have suggested that flow spillage forward of the blade passage triggers the onset of stall. Adamczyk et al. (1993) performed numerical simulations similar to those used herein which indicate that at a near stall operating point, spillage of low-energy fluid in the clearance flow drives the shock further forward, altering the upstream wave pattern, reducing the mass flow rate, and increasing the blade incidence angle. This process resulted in a steady reduction in mass flow rate as the simulation time proceeded, and ultimately lead to numerical stall. While it is not clear whether spillage and high incidence cause stall, it does appear that there is a strong link between the presence of these flow features and the onset of stall. The present experimental results are therefore investigated in more detail for evidence of these flow features at the near-stall operating condition.

Relative velocity vectors measured at $90 \%$ and $95 \%$ span for the near-stall flow point are shown in Figure 5 along with the shock front location as depicted by the relative Mach number contour level of 1.2. The vectors are presented at every 5\% chord in the axial direction. For the sake of clarity, vectors are plotted for every eighth circumferential location at which data was acquired. The length of each vector indicates the magnitude of the relative velocity normalized by the maximum velocity in each respective plot.

At $90 \%$ span, which is relatively free from tip clearance flow effects, the flow just downstream of the shock is turned toward the pressure surface, resulting in a slight increase in incidence angle at the nose of the blade. In contrast, at $95 \%$ span the interaction of the leakage vortex and the passage shock results in a large region of high relative flow angle downstream of the shock. The relative flow in this region is nearly tangential, indicating that the axial velocity is near zero in this region. The fluid in this region is moving toward the pressure surface, contributing to a high incidence angle at the nose of the blade. It seems plausible that any further increase in rotor backpressure will lead to a stall of the blade section at $95 \%$ span.

In summary, the experimental results shown in Figure 5 suggest that flow blockage caused by the shock/vortex interaction results in axial velocities which are nearly zero in the interaction region. This in turn generates high relative flow angles near the nose of the blade. These results suggest that an alleviation of the blockage generated by the shock / vortex interaction by using casing treatment or alternate blade tip designs could result in an increase in stable operating range by reducing the incidence angle at the blade tip.

Radial Extent of the Clearance Flow. Thus far we have examined the flow along a blade-to-blade streamsurface. We will now consider the radial extent of the shock/vortex interaction by presenting measured Mach number distributions on cross-channel $(\mathrm{R}-\theta)$ planes at the axial stations shown in Figure 3. The first axial location to be discussed is $20 \%$ chord, which corresponds to the approximate location of the shock/vortex interaction. The second axial plane is located just downstream of the blade at $108 \%$ rotor chord, where the impact of the clearance vortex on the rotor wake structure is evident. The final axial location to be presented is located at $138 \%$ rotor chord and coincides with the location of the stator leading edge plane if the stator was installed. Comparison of the results obtained at $108 \%$ and $138 \%$ chord will be used to illustrate the mixing of the clearance flow downstream of the rotor.

The cross-channel Mach number distributions at $20 \%$ chord are presented in Figure 6a. The white regions adjacent to the blade surfaces denote areas in which measurements could not be acquired due to optical blockage. The Mach number contours are incremented by 0.1 . The distortion of the rotor shock, as 


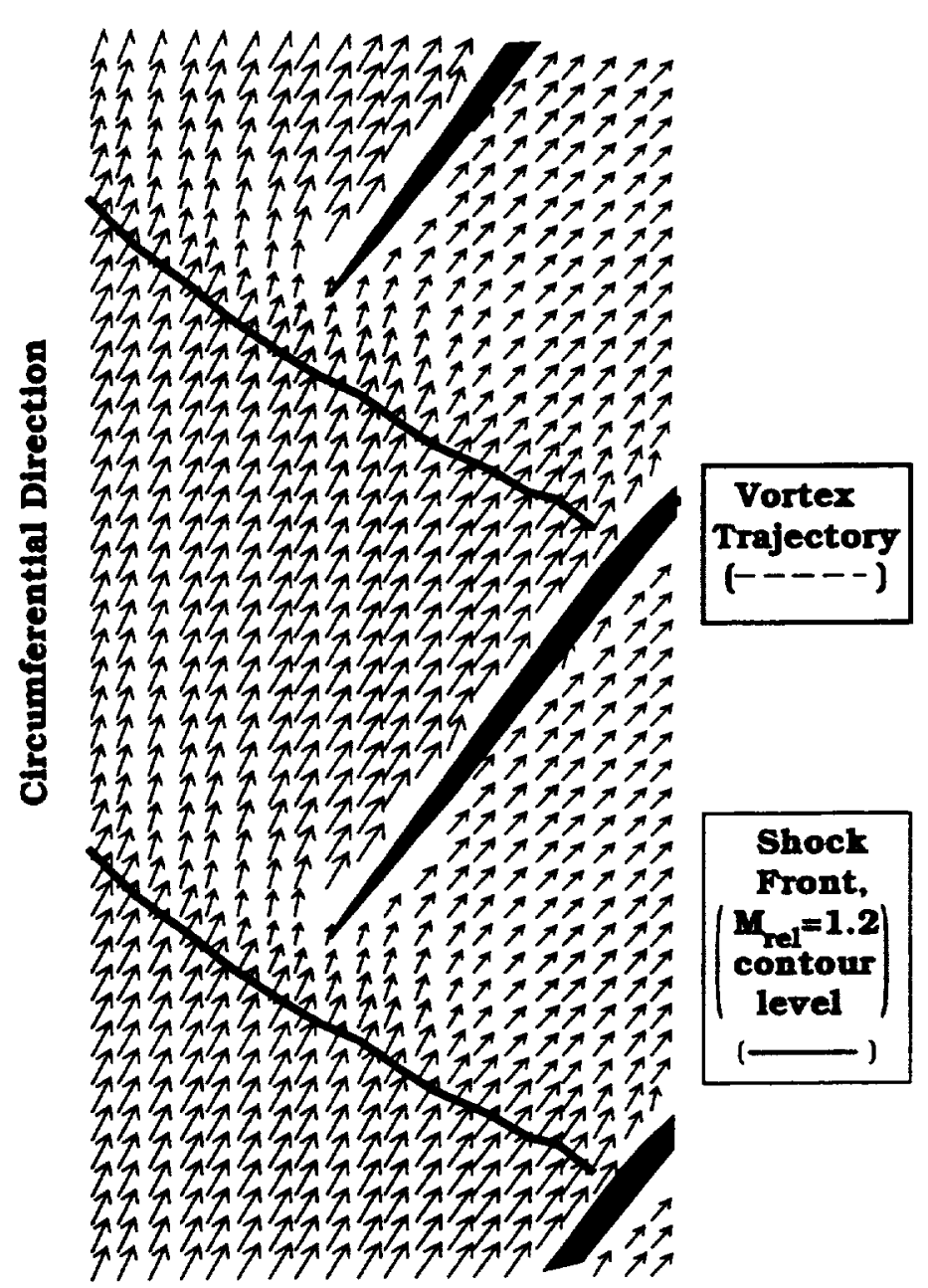

Arial Direction

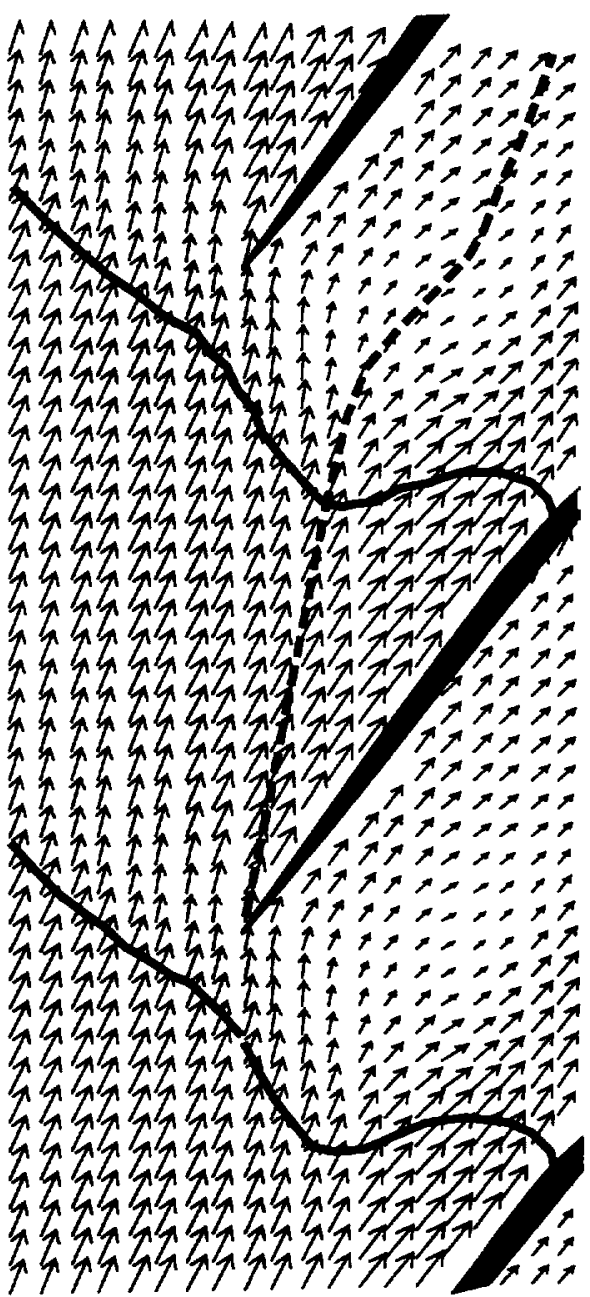

Axial Direction

a) $90 \%$ Span

b) $95 \%$ Span

FIGURE 5. MEASURED RELATIVE VELOCITY VECTORS AT 90\% AND 95\% SPAN FOR THE NEAR STALL OPERATING CONDITION AT DESIGN SPEED.

depicted by the Mach contours bending toward the blade suction surface near the endwall, is seen for both operating conditions. Both the circumferential and radial extent of the blockage region are larger near stall. The shock distortion which results from the shock/vortex interaction penetrates to approximately $93 \%$ span for the near peak efficiency case and to $90 \%$ span for the near stall case. Recall that the measured tip clearance is approximately $0.5 \%$ of span. Therefore, the influence of the clearance flow can be seen over a radial extent which is approximately 20 times the physical clearance in this transonic compressor.

Mixing Downstream of the Rotor. The cross-channel Mach number distributions at $108 \%$ of rotor chord are presented in Figure 6b in order to study the behavior of the clearance flow downstream of the rotor. Note the color bar has been changed from that of Figure $6 \mathrm{a}$, and that the Mach number contours are now incremented by 0.025 . The peak efficiency results clearly indicate that the rotor wake is asymmetric outboard of about $90 \%$ span due to the presence of low Mach number fluid (with Mach numbers in the range $0.55-0.75$ ) in the pressure surface/shroud comer of the flow field. Recall that the measured blade-to-blade Mach number distributions indicated that the low Mach number region downstream of the shock/vortex interaction migrates to the blade pressure surface and impacts on the surface before reaching the blade trailing edge. It therefore seems plausible that the low Mach number fluid in the pressure surface / shroud comer represents the remnants of the clearance vortex as it exits the blade passage. Turning to the near stall case, we see that the wake is also asymmetric in the outer $10 \%$ of blade span. However, in the near stall case, it appears that the low Mach number fiuid occupies the entire blade pitch outboard of $95 \%$ span.

The cross-channel Mach number distributions at $138 \%$ chord are shown in Figure $6 \mathrm{c}$. Note that this is the stator leading edge plane, although the stator was not installed during this investiga- 


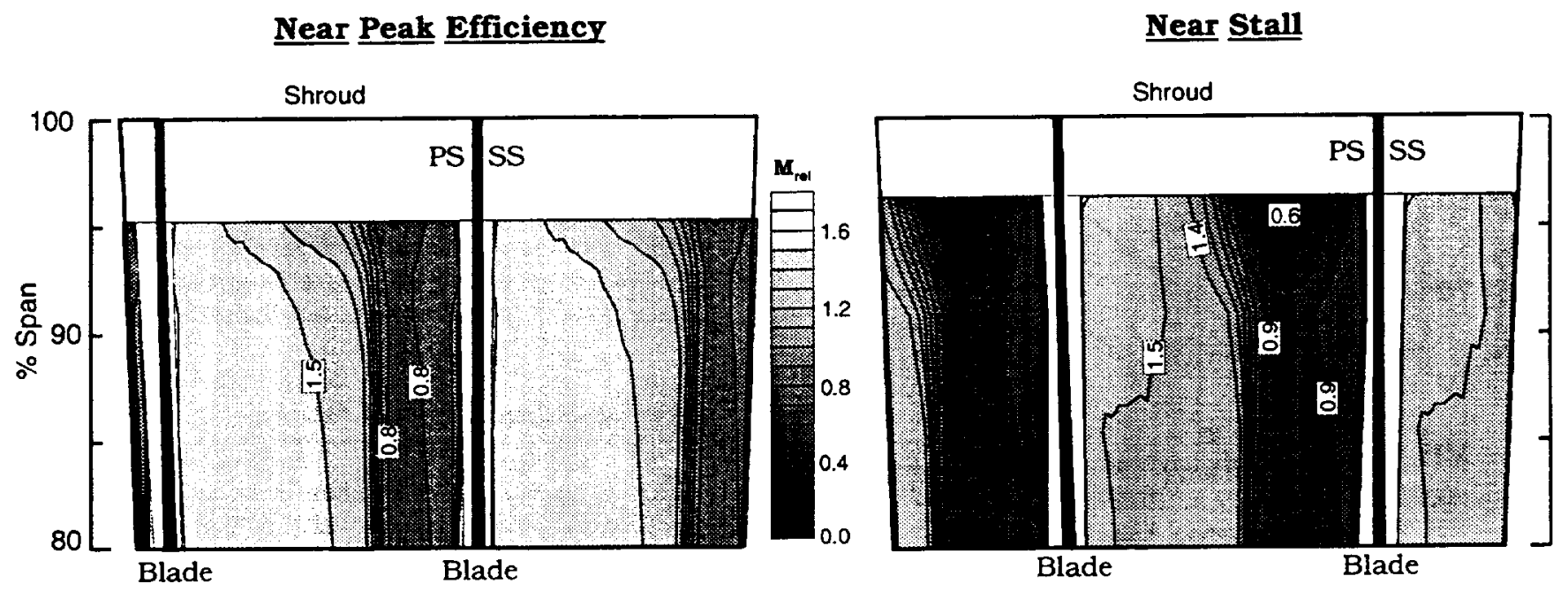

a) $20 \%$ Rotor Chord
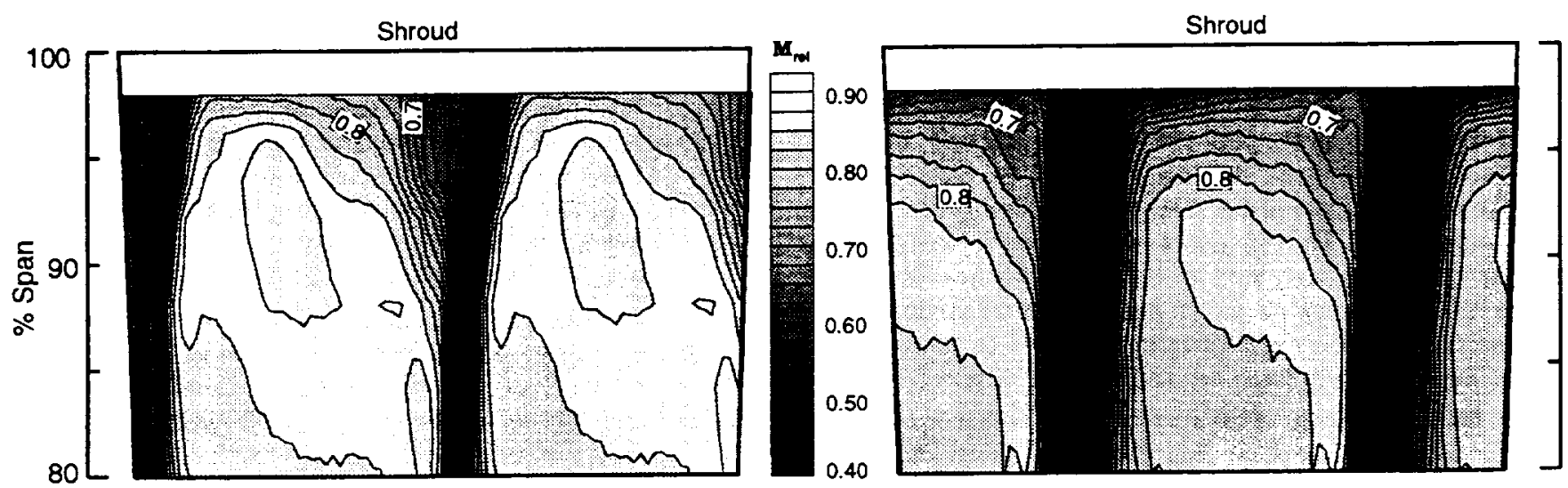

b) $108 \%$ Rotor Chord
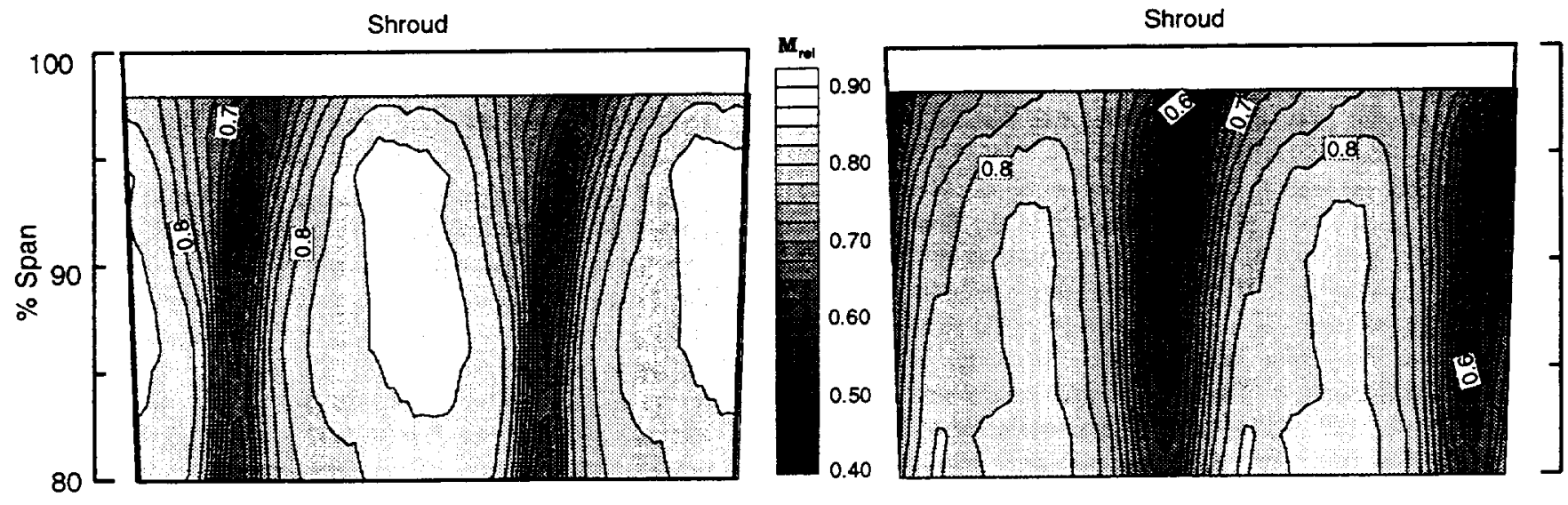

c) $138 \%$ Rotor Chord

FIGURE 6. MEASURED CROSS-CHANNEL MACH NUMBER DISTRIBUTIONS AT DESIGN SPEED FOR NEAR PEAK EFFICIENCY (LEFT COLUMN) AND NEAR STALL (RIGHT COLUMN) OPERATING CONDITION. 


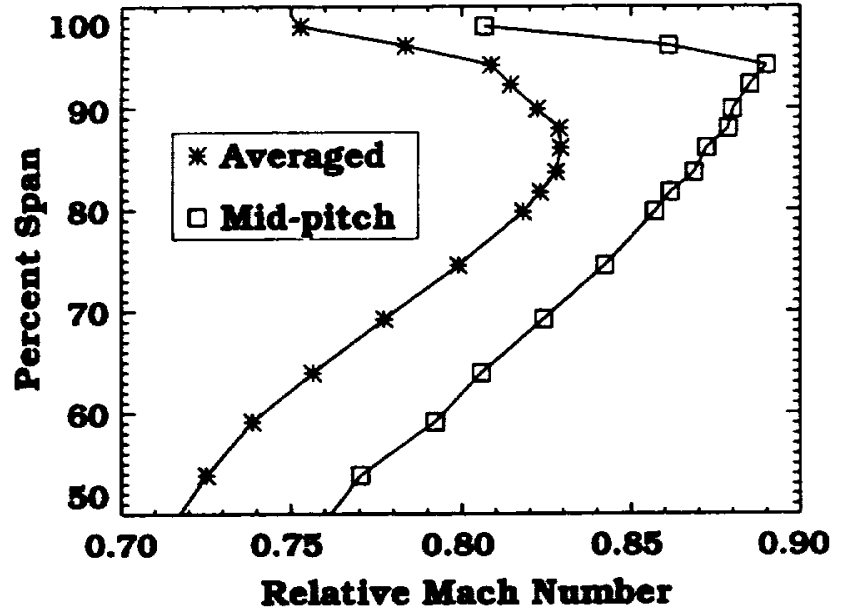

FIGURE 7. A COMPARISON OF THE AREA - AVERAGED AND MID-PITCH VALUES OF THE MEASURED RELATIVE MACH NUMBER AT $138 \%$ ROTOR CHORD FOR THE PEAK EFFICIENCY OPERATING CONDITION.

tion. At this location the rotor wakes are nearly symmetric about their centerline. The rotor wakes begin to widen at about $85 \%$ and $80 \%$ of span for the peak efficiency and near stall conditions, respectively. However, it is not clear that the increased wake width near the shroud is due soley to the continued mixing of the clearance vortex. The radial-outward migration of fluid within the blade wakes also contributes to wake widening near the shroud. The results in Figure $6 \mathrm{~b}$ and $6 \mathrm{c}$ indicate that the mixing process downstream of the rotor is complex and is still in progress by the time the flow would reach the stator leading edge.

A final observation on the results shown in Figure 6 concerns the concept of an "endwall boundary layer" downstream of the rotor. Consider the radial gradient in Mach number at mid-pitch in the peak efficiency results at $108 \%$ and $138 \%$ chord. The radial gradient is quite small at immersions below $97 \%$ span, indicating that the endwall boundary layer thickness at mid-pitch is only about $3 \%$ of span. However, a pitchwise average of the flow field would indicate a considerably thicker endwall boundary layer, since the average will be weighted by the presence of the low Mach number levels within the widened wakes which result from the merging of the clearance vortex fluid with the blade wake fluid. Low-response instrumentation such as total pressure probes, which cannot respond to flow fluctuations at the blade passing frequency, yield such a pitchwise average of the flow field. To illustrate this point the Mach number distribution at $138 \%$ rotor chord for the near peak efficiency operating condition was areaaveraged in the pitchwise direction at each radial location and is compared to the relative Mach number at mid-pitch between the blade wakes in Figure 7. The area-averaged results indicate a rolloff in relative Mach number at $86 \%$ span compared to $94 \%$ span for the mid-pitch results. Since the mid-pitch results are more indicative of the casing boundary layer, care must be exercised when using low-response instrumentation to measure the endwall boundary layer.

In summary, at design speed the interaction between the rotor passage shock and the tip leakage vortex generates a blockage in the passage. This blockage moves forward and becomes larger in both the circumferential and radial directions with increased rotor backpressure. At near stall operating conditions, the blockage associated with the shock/vortex interaction leads to high incidence angles near the blade tip and spillage of flow around the nose of the blade. Within the rotor blade passage, the clearance flow effects extend over the outer $10 \%$ of blade span. Remnants of the clearance vortex exit the rotor in the pressure surface / shroud comer of the flow field and mix into the rotor wake.

\section{Part Speed Computational Results}

To investigate the tip leakage flow in the absence of the passage shock the compressor was operated at $60 \%$ of design speed at the same flow coefficient as the near peak efficiency case at design speed. Analogous to the design speed case, computational results are presented first in order to identify key features associated with the tip clearance flow and to aid in the interpretation of the experimental results. At $60 \%$ speed the centrifugal force on the rotor blade is only $36 \%$ of that at design speed, resulting in a larger tip clearance and a change in blade untwist of approximately $0.5^{\circ}$. The computations to be presented for $60 \%$ speed utilized the same blade geometry as that used at design speed and therefore did not account for the change in blade twist. The $60 \%$ speed tip clearance was measured to be $0.584 \mathrm{~mm}(0.023 \mathrm{in}$.) or $1 \%$ of rotor tip chord and the computations presented herein do account for this increase in clearance relative to the design speed condition.

The predicted relative Mach number contours and normalized relative dynamic head contours are shown in Figure $8 \mathrm{a}$ and $8 \mathrm{~b}$, respectively. These contours are drawn in increments of 0.05 for the blade-to-blade streamsurface at $98 \%$ span. The regions of low Mach number and low relative dynamic head coincide and indicate the path of the tip leakage vortex and the location of the blockage associated with the vortex. The trajectory of the tip leakage vortex at $60 \%$ design speed is similar to that predicted at design speed. However, there is a second region of low Mach number which first appears near the trailing edge of the blade at about $15 \%$ pitch from the suction surface. An island of low relative dynamic head in this region confirms that there is an additional source of blockage. Particle pathlines were studied in order to determine the source of this second region of low Mach number and low relative dynamic head.

The formation of the tip leakage vortex emanating from the blade leading edge is depicted by the pathlines of particles which pass through the clearance gap and is shown in Figure 8c. Note that Figure $8 \mathrm{c}$ is a view of the pathlines as seen by an observer looking radially inward toward the hub. Particles released in the clearance gap over the first $35-40 \%$ of rotor chord are entrained in the leakage vortex. However, for clarity, the fluid particles released over only the first $20 \%$ of rotor chord are shown. Particles which pass through the clearance gap in the front portion of the blade roll-up into a vortex whose trajectory is coincident with the regions of low Mach number and low relative dynamic head which start at the leading edge and cross the passage toward the pressure surface. The pathlines of fluid particles which pass through the clearance gap over the last $60 \%$ of rotor chord (not 


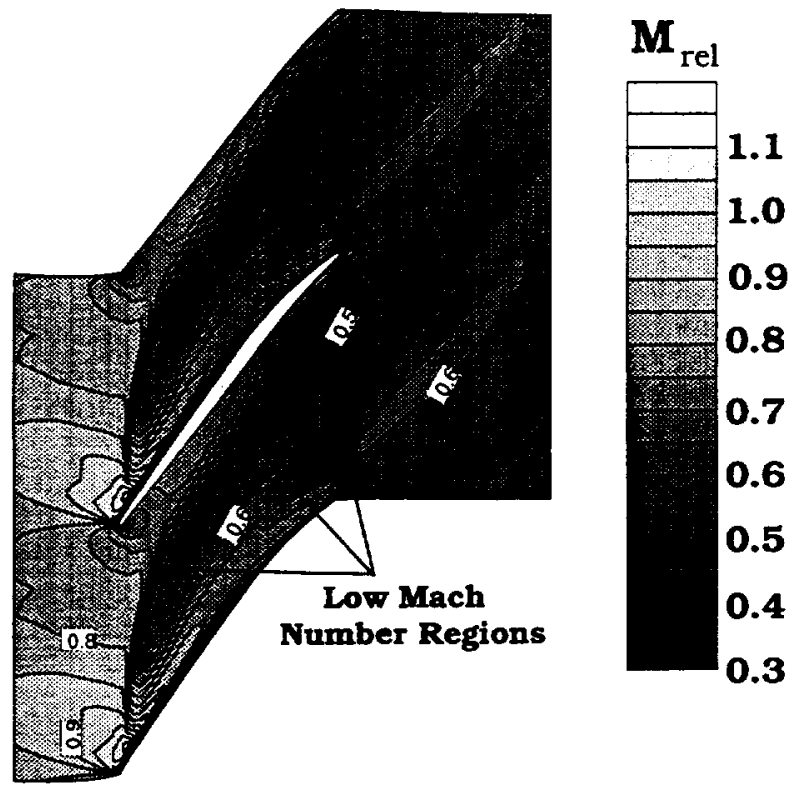

a) Relative Mach number distribution at $98 \%$ span.

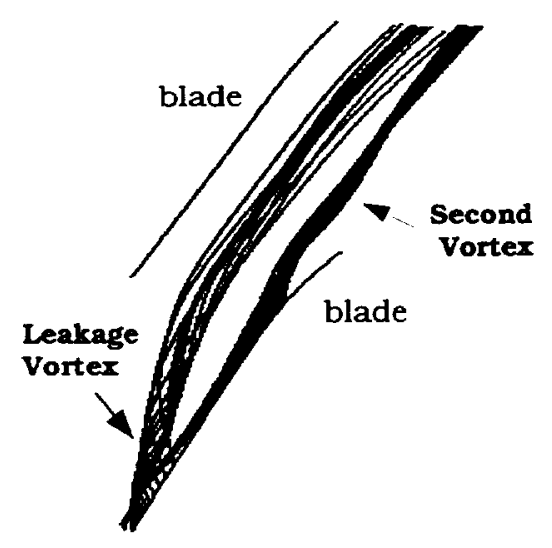

c) Blade-to-blade view of particle traces indicating the formation of the leakage and second vortex.

FIGURE 8. COMPUTATIONAL RESULTS AT 60\% SPEED.

shown) do not indicate a roll-up into a vortex. Furthermore, the trajectory of these pathlines does not coincide with the low Mach number region which emanates near the blade trailing edge. To determine the origin of the fluid in this second low Mach number region, particles were released within the region and traced backwards in time. The resulting pathlines are shown in Figure

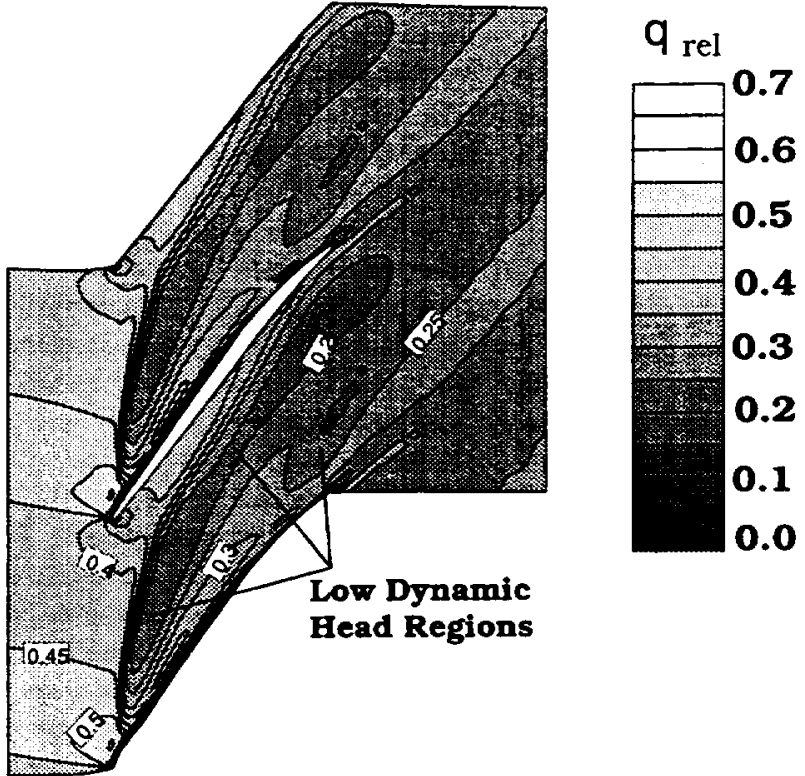

b) Relative dynamic head at $98 \%$ span.

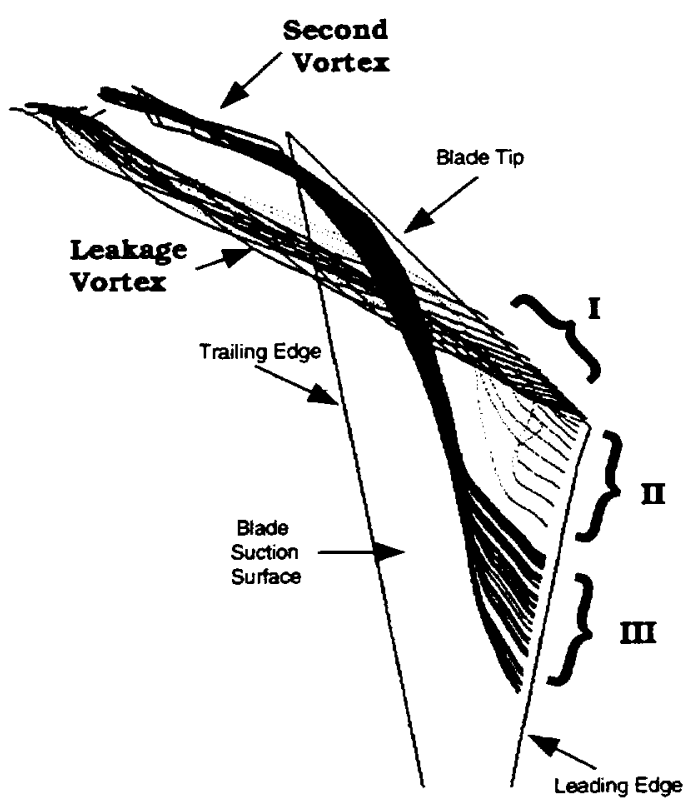

d) Perspective view of particle traces indicating the formation of the leakage and second vortex.

$8 \mathrm{c}$ and are denoted as the 'second vortex'. It is important to note that the fluid forming the second vortex does not pass through the rotor tip clearance gap.

Why does this second vortex form at part speed and not at design speed? For the $60 \%$ speed near peak efficiency operating condition the blade incidence is positive and results in a small 
region of supersonic flow at the suction surface near the leading edge as indicated in Figure 8a. This supersonic region at the leading edge extends over the outer $70 \%$ span. At the downstream edge of the supersonic region the flow encounters an adverse pressure gradient which results in a radial migration of fluid along the blade suction surface. The fluid climbing up the suction surface encounters the leakage fluid at the blade tip and rolls-up into a vortex. These flow features are depicted by particle pathlines in Figure $8 d$, which is a perspective view of approximately the outer $15 \%$ of blade span. The pathlines of particles released in the clearance gap over the first $20 \%$ chord, indicated by group ' $I$ ' in Figure 8d, illustrate the formation of the leakage vortex. Particles released near the suction surface, indicated by groups 'II' and 'III', tum radially upward within the first $10 \%$ rotor chord. This radial migration occurs at the trailing edge of the supersonic region, where the flow encounters the adverse pressure gradient. Particles released along the suction surface from 96-99\% span (group 'II') are entrained in the leakage vortex. Therefore, the leakage vortex not only consists of fluid which has passed over the rotor tip, but also includes fluid from the suction surface boundary layer. The second vortex develops from particles originating at $90-95 \%$ span near the suction surface leading edge (group 'III'). Though not evident from the perspective illustrated in Figure 8d, the second vortex lies entirely below the tip clearance region. The radial migration of the fluid along the suction surface is the key to the formation of the second vortex. At design speed the flow along the suction surface is expanding behind the shock in a favorable pressure gradient. Particle traces at design speed indicate virtually no radial migration upstream of the shock and downstream of the shock the radial migration is small. In addition, a computation was performed at $60 \%$ speed using the same tip clearance as that at design speed, which represents a $40 \%$ reduction in clearance. The second vortex still developed and the radial migration of fluid near the suction surface still occured. Therefore, the formation of the second vortex is not related to the strength of the clearance flow but rather is due to the secondary flows along the blade suction surface that result from operating at an off-design condition. Laser anemometer data acquired at both $60 \%$ speed (discussed below) and $80 \%$ speed (not discussed herein) confirm the presence of this second vortex. It seems plausible that the formation of the second vortex is not specific to this machine, but could exist on many transonic blades operated at off-design conditions.

\section{Part Speed Experimental Results}

Laser anemometer measurements were acquired along the $95 \%$ span streamsurface for the $60 \%$ design speed case at near peak efficiency. The experimental results are presented in terms of relative Mach number in Figure 9. The Mach number contours and color bar are identical to those used for the computational results presented in Figure 8a. The white areas in Figure 9 indicate regions in which laser anemometer measurements could not be made due to reflections from the blades and optical blockage of the laser beam paths by the blades. The measured Mach number distribution confirms the numerically predicted region of

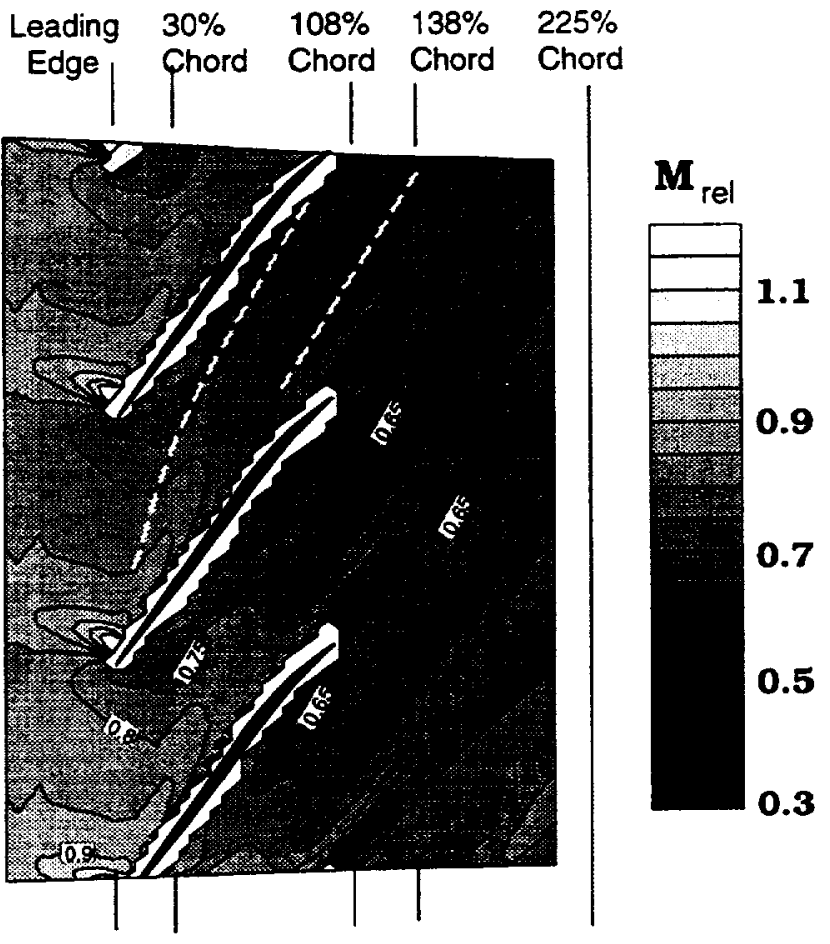

FIGURE 9. MEASURED RELATIVE MACH NUMBER CONTOURS AT $95 \%$ SPAN [..........ESTIMATED CLEARANCE VORTEX PATH].

supersonic flow near the leading edge. Based on the deflections of the Mach number contours, the paths of the leakage and second vortex were estimated and are shown by the dashed lines in Figure 9. Within the blade passage, the trajectory of the tip leakage vortex which originates at the leading edge is similar to that observed at $100 \%$ speed in that it migrates across the blade passage and intersects the pressure surface near the blade trailing edge. The path of the second vortex is reflected in the measured Mach number distribution and is in qualitative agreement with the predicted path shown in Figure 8c.

Radial Extent \& Downstream Mixing. The Mach number distributions determined from laser anemometer surveys in a cross-channel plane are presented at four axial locations in Figure 10 to illustrate the radial extent and the mixing process for both vortices. The scale of all four plots is held constant, however the radial extent of each plot may vary somewhat because each axial location was surveyed over slightly different areas. The Mach number contours are incremented by 0.025 and the color scale is identical for all four plots. The white regions adjacent to the blade surfaces in the $30 \%$ chord plot are the regions in which measurements could not be acquired due to optical blockage.

The leakage vortex emanating from the leading edge of the blade will be referred to as Vortex ' $A$ ' and that formed in the rear half of the blade near the suction surface will be referred to as Vortex 'B'. Tip leakage Vortex 'A' is shown in Figure 10a at the $30 \%$ chord location. The leakage vortex is located near midpitch and exhibits a radial penetration of about $5 \%$ of span and a circumferential extent of about $50 \%$ of blade pitch. Note 


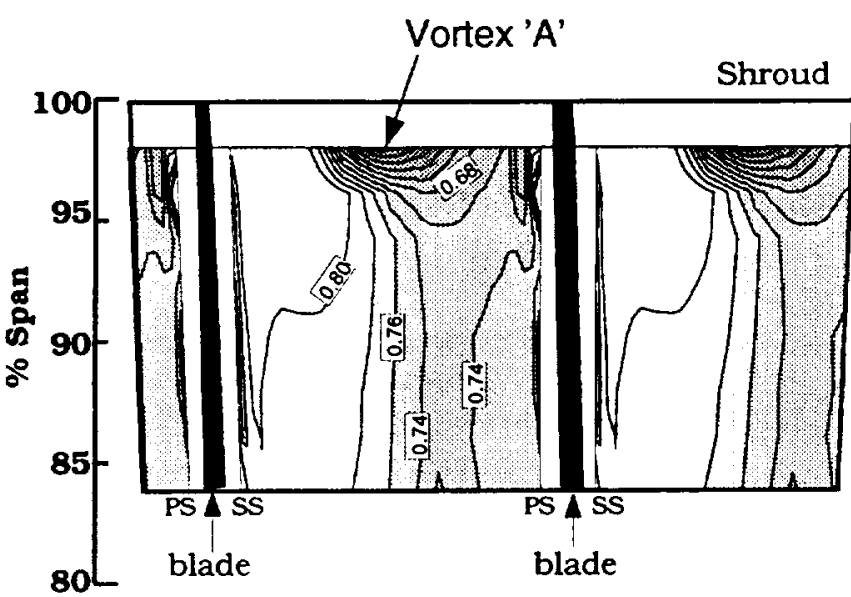

a) $\mathbf{3 0} \%$ Rotor Chord

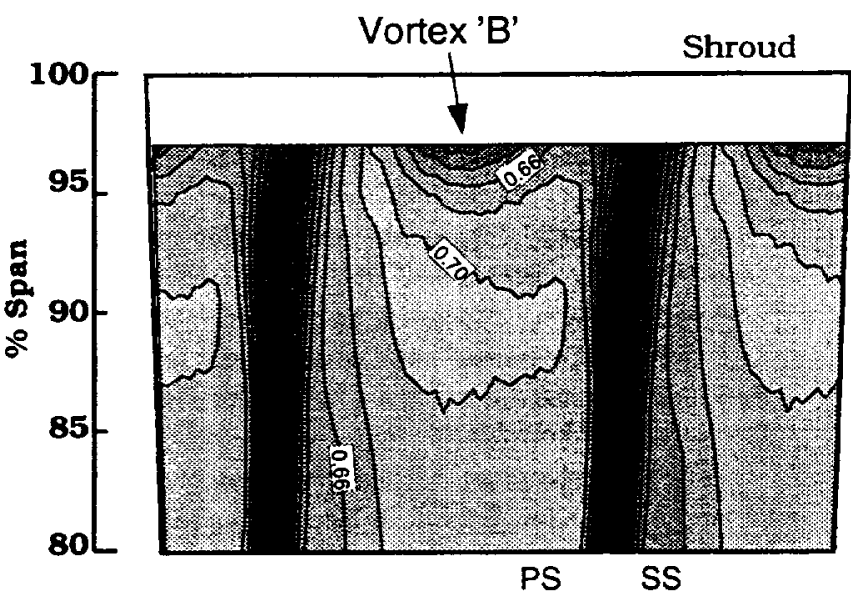

c) $138 \%$ Rotor Chord

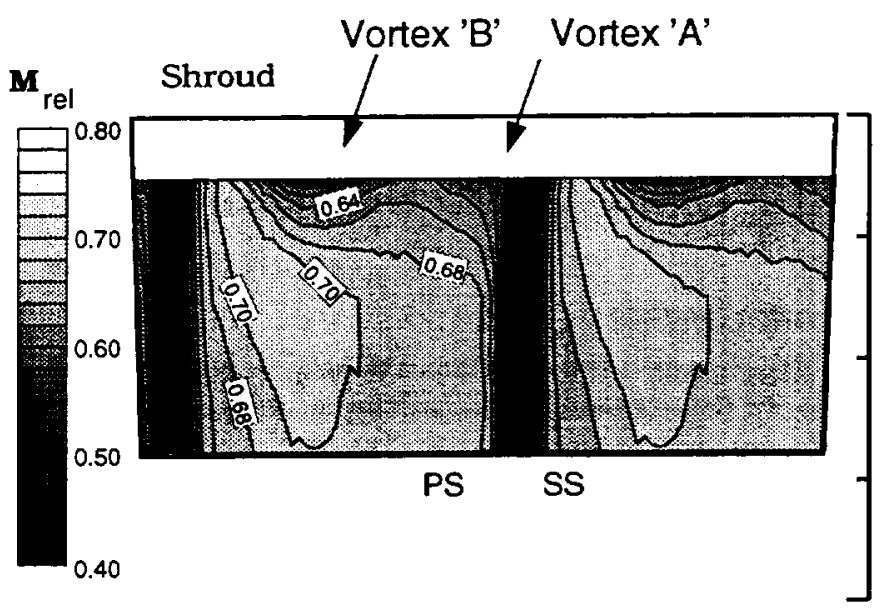

b) $108 \%$ Rotor Chord
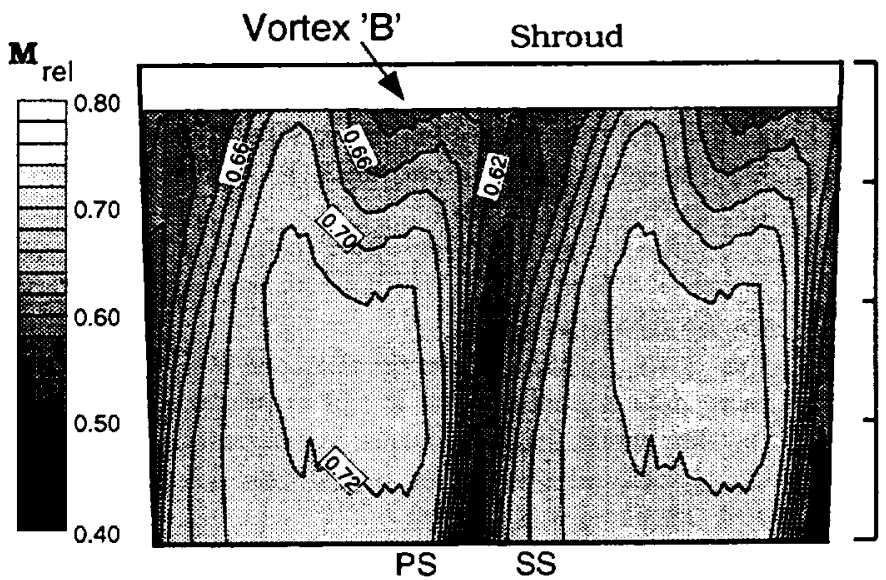

d) $\mathbf{2 2 5} \%$ Rotor Chord

FIGURE 10. MEASURED CROSS-CHANNEL MACH NUMBER DISTRIBUTIONS AT 60\% SPEED OPERATING AT NEAR PEAK EFFICIENCY.

that even though the tip clearance at part speed is double that of design speed, the radial extent of the leakage flow is about half of that at design speed at this axial location. This difference in radial extent is due to the enlargement of the tip leakage vortex when it encounters the shock at design speed.

As shown in the blade-to-blade Mach number distribution in Figure 9, Vortex 'A' moves across the passage and impacts on the pressure surface before reaching the blade trailing edge. Therefore, in the Mach number distribution measured at $108 \%$ chord, Figure 10b, Vortex ' $A$ ' accounts for the low Mach number fluid in the pressure surface/shroud comer of the flow field. This behavior is similar to that of the leakage vortex at design speed. The region of low Mach number fuid at mid-pitch above $94 \%$ span corresponds to Vortex 'B'. At $138 \%$ chord, shown in Figure $10 \mathrm{c}$, Vortex ' $A$ ' has mixed with the rotor wake and is no longer detectable while Vortex ' $B$ ' has undergone very little mixing. In fact Vortex 'B' has not mixed out by $225 \%$ chord as shown in Figure 10d. Furthermore, the Mach number deficit in the vortex is comparable to that of the blade wake. Therefore, the vortex that forms from suction surface boundary layer fluid and emanates from the rear half of the blade diffuses very slowly downstream of the blade. In the present compressor Vortex 'B' would reach the stator leading edge, located at $138 \%$ chord, intact. The impact of the blade wake and Vortex ' $B$ ' on the stator performance is a topic of future research. However, one point that has emerged is that at design speed, where the vortex and wake fluid have intermixed, the stator will be exposed to an unsteady flowfield generated at the rotor blade passing frequency, whereas at part speed the stator will be exposed to an unsteady flowfield generated by the rotor blade wakes plus Vortex ' $B$ ' in the endwall region.

In summary, at $60 \%$ speed operating conditions the leakage flow over the front portion of the rotor rolls into a vortex which moves across the blade passage, impacts on the pressure surface before reaching the trailing edge, and merges with the rotor wake downstream of the blade. A second vortex is formed by fluid which migrates radially outward along the suction surface and 
rolls up into a vortex when it encounters the tip leakage flow in the rear half of the blade. The second vortex exits the blade passage near midpitch and persists for more than one rotor chord downstream. At stations far downstream of the rotor this vortex exhibits a Mach number deficit comparable to that of the wake.

\section{CONCLUSIONS}

Experimental and computational techniques are used to investigate the flow physics of the endwall region within and downstream of a transonic compressor rotor. The rotor is operated at $100 \%$ and $60 \%$ of design speed which provides an inlet relative Mach number at the rotor tip of 1.5 and 0.9 , respectively.

The conclusions of this investigation at design speed are:

1. The strong interaction between the rotor passage shock and the tip leakage vortex generates a region of high blockage in the passage which moves forward and becomes larger in both the circumferential and radial directions as the rotor loading is increased.

2. The shock/vortex interaction and ensuing blockage leads to high incidence angles at the blade tip, which may play a role in triggering tip stall.

3. The influence of the shock/vortex interaction extends over the outer $10 \%$ of span, which is a distance equal to 20 times the tip clearance gap.

4. The mixing process of the tip clearance flow with the primary flow is complex and is still in progress by the time the flow would reach the stator leading edge plane in this closely-coupled compressor stage (interblade gap equal to $40 \%$ rotor chord at the tip).

The conclusions of this investigation at part speed, in the absence of the shock, are:

1. A second vortex forms along the suction surface near the blade trailing edge as fluid within the suction surface boundary layer migrates outward and encounters the tip clearance flow over the rear half of the blade. This second vortex develops as a result of operating at an off-design condition and does not exist at design speed.

2. The second vortex persists for more than one rotor chord downstream and exhibits a relative Mach number deficit which was comparable to that of the blade wake.

3. Although the rotor tip clearance at part speed is double that at design speed, the radial extent of the leakage flow within the blade passage at part speed is about half of that at design speed. This difference in radial extent is caused by the enlargement of the leakage vortex when it encounters the rotor passage shock which is present under design speed conditions.

\section{ACKNOWLEDGEMENTS}

The authors wish to acknowledge the efforts of Dr. Tony Strazisar of NASA Lewis Research Center for his guidance not only in the writing of this paper, but also in acquiring and analyzing the experimental data. We are also grateful to $\mathrm{Dr}$. John Adamczyk of NASA Lewis Research Center and Dr. Ed Greitzer of Massachusetts Institute of Technology for their helpful comments and suggestions.

\section{REFERENCES}

Adamczyk, J.J., Celestina, M.L., and Greitzer , E.M., 1993, "The Role of Tip Clearance in High-Speed Fan Stall," ASME Journal of Turbomachinery, Vol. 115, pp 28-38.

Adamczyk, J.J., Celestina, M.L., Beach, T.A., and Bamett, M., 1989, "Simulation of Three-Dimensional Viscous Flow Within a Multi-Stage Turbine," ASME Journal of Turbomachinery, Vol 112, No 3, pp 370-376.

Chen, G.T., Greitzer, E.M., Tan, C.S., and Marble, F.E.,1991, "Similarity Analysis of Tip Clearance Flow Structure," ASME Journal of Turbomachinery, Vol 113, pp 260-271.

Copenhaver, W.W., Hah, C., and Puterbaugh, S.L., 1992 , "Three-Dimensional Flow Phenomena in a Transonic, HighThrough-Flow, Axial-Flow Cmpressor Stage," ASME Paper No. 92-GT-169.

Crook, A., 1989, "Numerical Investigation of EndwallVasing Treatment Flow Phenomena," M.S. Thesis, MIT.

Hathaway, M.D., Chriss, R.M., Wood, J.R., and Strazisar, A.J., 1993, "Experimental and Computational Investigation of the NASA Low-Speed Centrifugal Compressor Flow Field," ASME Joumal of Turbomachinery, Vol. 115, pp 527-542.

Inoue, M., Kuroumaru, M., and Fukuhara, M., 1986, "Behavior of Tip Leakage Flow Behind an Axial Compressor Rotor," ASME Journal of Engineering for Gas Turbines and Power, Vol. 108, pp. 7-13.

Inoue, M. and Kuroumaru, M., 1989, "Structure of Tip Clearance Flow in an Isolated Axial Compressor Rotor, "ASME Journal of Turbomachinery, Vol. 111, pp 250-256.

Kirtley, K.R., Beach, T.A., and Adamczyk, J.J., 1990, "Numerical Analysis of Secondary Flow in a Two-Stage Turbine," AIAA-90-2356.

McDougall, N.M., Cumpsty, N.A., and Hynes, T.P., 1990, "Stall Inception in Axial Compressors," ASME Joumal of Turbomachinery, Vol. 112, pp 116-125.

McDougall, N.M., 1990, "A Comparison Between the Design Point and Near Stall Performance of an Axial Compressor," ASME Journal of Turbomachinery, Vol. 112, pp 109-115.

Moore, R.D., and Reid, L., 1980, "Performance of Single-Stage Axial-Flow Transonic Compressor with Rotor and Stator Aspect Ratios of 1.19 and 1.26, Respectively, and with Design Pressure Ratio of 2.05," NASA TP 1659.

Nichols, C. E. Jr., 1987, "Preparation of Polystyrene Microspheres for Laser Velocimetry in Wind Tunnels," NASA TM 89163.

Reid, L., and Moore, R.D., 1978, "Design and Overall Performance of Four Highly Loaded, High-Speed Inlet Stages for an Advanced High-Pressure Ratio Core Compressor," NASA TP 1337. 
Stauter, R.C., 1992, "Measurement of the Three-Dimensional Tip Region Flowfield in an Axial Compressor," ASME 92-GT211.

Storer, J.A. and Cumpsty, N.A., 1993, "An Approximate Analysis and Prediction Method for Tip Clearance Loss in Axial Compressors," ASME 93-GT-140.

Strazisar, A.J., Wood, J.R., Hathaway, M.D., and Suder, K.L., 1989, "Laser Anemometer Measurements in a Transonic Axial-
Flow Fan Rotor," NASA TP 2879.

Urasek, D.C., and Janetzke, D.C., 1972, "Performance of Tandem-Bladed Transonic Compressor Rotor with Rotor Tip Speed of 1375 Feet per Second," NASA TM X-2484.

Wisler, D.C., 1985, "Loss Reduction in Axial-Flow Compressors Through Low-Speed Model Testing," ASME Journal of Turbomachinery, Vol. 107, pp 354-363. 
Public reporting burten for this collaction of inlomation is estimated to average 1 hour per response, including the time for reviewing instructions, searching existing data sources, Pathering and maintaining the data needed, and completing and reviawing the collection of information. Send comments regarding this burden estimate or ary other aspect of this gallering a of in Davis Highwey, Suite 1204. Artington. VA 22202-4302. and to the Office of Management and Budget, Paperwork Reduction Project (0704-0188), Wastington, DC 20503.

\begin{tabular}{|l|l|l|}
\hline 1. AGENCY USE ONLY (Leave blank) & $\begin{array}{c}\text { 2. REPOAT DATE } \\
\text { June } 1995\end{array}$ & $\begin{array}{l}\text { 3. REPOAT TYPE AND DATES COVEAED } \\
\text { Technical Memorandum }\end{array}$ \\
\hline 4.
\end{tabular}

\section{TITLE AND SUBTTLE}

5. FUNDING NUMBERS

Experimental and Computational Investigation of the Tip Clearance Flow in a Transonic Axial Compressor Rotor

\section{AUTHOR(S)}

Kenneth L. Suder and Mark L. Celestina

$$
\text { WU-505-62-52 }
$$

\section{PERFOAMMG ORGANRATION NAME(S) AND ADDRESS(ES)}

National Aeronautics and Space Administration

Lewis Research Center

Cleveland, Ohio 44135-3191

8. PERforming ORGanization REPORT NUMBER

E-9076

9. SPONSORIMGMONITORING AGENCY NAME(S) AND ADDRESS(ES)

National Aeronautics and Space Administration

Washington, D.C. 20546-0001

NASA TM-106711

11. SUPPLEMENTAAY NOTES

Prepared for the 39th International Gas Turbine and Aeroengine Congress and Exposition sponsored by the American Society of Mechanical Engineers, The Hague, Netherlands, June 13-16, 1994. Kenneth L. Suder, NASA Lewis Research Center and Mark L. Celestina, Sverdrup Technology, Inc., Lewis Research Center Group, Brook Park, Ohio 44142 (work funded by NASA Contract NAS3-25266), presently at NYMA, Inc., Engineering Services Division, 2001 Aerospace Parkway, Brook Park, Ohio 44142. Responsible person, Kenneth L. Suder, organization code 2640, (216) 433-5899.

12a. DISTRIBUTIONVAVAILABHLITY STATEMENT 12b. DISTRIBUTION CODE

Unclassified - Unlimited

Subject Categories 02 and 34

This publication is available from the NASA Center for Aerospace Information, (301) 621-0390.

13. ABSTRACT (Reximum 200 mords)

Experimental and computational techniques are used to investigate tip clearance flows in a transonic axial compressor rotor at design and part speed conditions. Laser anemometer data acquired in the endwall region are presented for operating conditions near peak efficiency and near stall at $100 \%$ design speed and at near peak efficiency at $60 \%$ design speed. The role of the passage shock/leakage vortex interaction in generating endwall blockage is discussed. As a result of the shock/vortex interaction at design speed, the radial influence of the tip clearance flow extends to 20 times the physical tip clearance height. At part speed, in the absence of the shock, the radial extent is only 5 times the tip clearance height. Both measurements and analysis indicate that under part-speed operating conditions a second vortex, which does not originate from the tip leakage flow, forms in the endwall region within the blade passage and exits the passage near midpitch. Mixing of the leakage vortex with the primary flow downstream of the rotor at both design and part speed conditions is also discussed.

14. SUBJECT TERINS

Tip leakage vortex; Tip clearance vortex; Laser anemometry; Transonic compressor; Vortex/shock interaction

\begin{tabular}{|c|c|}
\hline $\begin{array}{c}\text { 17. SECURTY CLASSIFICATION } \\
\text { OF REPORT } \\
\text { Unclassified }\end{array}$ & $\begin{array}{c}\text { 18. SECURITY CLASSIFICATION } \\
\text { OF THIS PAGE } \\
\text { Unclassified }\end{array}$ \\
\hline
\end{tabular}

19. SECUFIT CLASSIFCATION OF ABSTRACT Unclassified
15. NUMBER OF PAGES

17

16. PRICE CODE

$\mathrm{A} 03$ 